\title{
Experimental mycobacteriosis in striped bass Morone saxatilis
}

\author{
D. T. Gauthier ${ }^{1, *}$, M. W. Rhodes ${ }^{1}$, W. K. Vogelbein $^{1}$, H. Kator ${ }^{1}$, C. A. Ottinger ${ }^{2}$ \\ ${ }^{1}$ Department of Environmental and Aquatic Animal Health, Virginia Institute of Marine Science, College of William and Mary, \\ Gloucester Point, Virginia 23062, USA \\ ${ }^{2}$ United States Geological Survey, Leetown Science Center, National Fish Health Research Laboratory, \\ Kearneysville, West Virginia 25430, USA
}

\begin{abstract}
Striped bass Morone saxatilis were infected intraperitoneally with approximately $10^{5}$ Mycobacterium marinum, M. shottsii sp. nov., or M. gordonae. Infected fish were maintained in a flow-through freshwater system at 18 to $21^{\circ} \mathrm{C}$, and were examined histologically and bacteriologically at 2, 4, 6, 8, 17, 26, 36 and 45 wk post-infection (p.i.). M. marinum caused acute peritonitis, followed by extensive granuloma development in the mesenteries, spleen and anterior kidney. Granulomas in these tissues underwent a temporal progression of distinct morphological stages, culminating in well-circumscribed lesions surrounded by normal or healing tissue. Mycobacteria were cultured in high numbers from splenic tissue at all times p.i. Standard Ziehl-Neelsen staining, however, did not demonstrate acid-fast rods in most early inflammatory foci and granulomas. Large numbers of acid-fast rods were present in granulomas beginning at 8 wk p.i. Between 26 and 45 wk p.i., reactivation of disease was observed in some fish, with disintegration of granulomas, renewed inflammation, and elevated splenic bacterial densities approaching $10^{9}$ colony-forming units $\mathrm{g}^{-1}$. Infection with $M$. shottsii or $M$. gordonae did not produce severe pathology. Mild peritonitis was followed by granuloma formation in the mesenteries, but, with 1 exception, granulomas were not observed in the spleen or anterior kidney. $M$. shottsii and $M$. gordonae both established persistent infections in the spleen, but were present at densities at least 2 orders of magnitude less than $M$. marinum at all time points observed. Granulomas in the mesenteries of M. shottsii- and M. gordonaeinfected fish resolved over time, and no reactivation of disease was observed.
\end{abstract}

KEY WORDS: Mycobacteriosis - Striped bass · Morone saxatilis • Mycobacterium marinum • Mycobacterium gordonae $\cdot$ Mycobacterium shottsii $\cdot$ Granuloma Resale or republication not permitted without written consent of the publisher

\section{INTRODUCTION}

Mycobacterial infections are common in wild and captive fish stocks worldwide. Mycobacterium marinum, $M$. fortuitum, and $M$. chelonae are the most frequently reported isolates, but other species, including M. neoaurum, M. simiae, M. poriferae and $M$. scrofulaceum, have been cultured from infected fish (Backman et al. 1990, Landsdell et al. 1993, Tortoli et al. 1996, Bruno et al. 1998). Clinical signs of mycobacteriosis are nonspecific and may include scale loss, dermal ulceration, emaciation, exophthalmia, pigmentation changes, and spinal defects (Nigrelli \& Vogel
1963, Gómez et al. 1993, Bruno et al. 1998). Miliary granulomatous inflammation throughout the viscera is characteristic of mycobacteriosis, and enlargement of affected organs may occur (Colorni 1992). Histologically, granulomas resemble those found in mammalian mycobacterial infections, and acid-fast bacilli are usually present (Nigrelli \& Vogel 1963).

The striped bass, or rockfish, Morone saxatilis is among the numerous commercially or recreationally important fish species that are affected by mycobacteriosis. Outbreaks of mycobacteriosis have been described in wild and cultured populations of west coast striped bass, with prevalences reaching 68 and $80 \%$, 
respectively (Sakanari et al. 1983, Hedrick et al. 1987). Mycobacterium marinum was cultured from fish in the latter study, and has also been isolated from wild Pacific striped bass (Landsell et al. 1993). Recently, visceral and dermal lesions in striped bass from Chesapeake Bay and its tributaries were shown to be associated with mycobacterial infection (Vogelbein et al. 1999). An epizootiological study of striped bass from Virginia tributaries of Chesapeake Bay found up to $62.7 \%$ prevalence of mycobacteriosis, based on histological presence of characteristic granulomas. This suggests the disease has significant effects on wild stocks (Cardinal 2001).

In addition to Mycobacterium marinum and several other Mycobacterium spp., 2 recently described species of mycobacteria, ' $M$. chesapeaki' (Heckert et al. 2001) and M. shottsii (Rhodes et al. 2001, 2003 in press), have been isolated from Chesapeake Bay striped bass. Mycobacteria were cultured from splenic tissue of approximately $76 \%$ of striped bass that were collected from Chesapeake Bay or its tributaries and sampled bacteriologically. $M$. shottsii was the most frequently isolated, occurring in more than $70 \%$ of culture-positive samples and often reaching densities of $10^{4}$ to $10^{6}$ colony-forming units per gram ( $\mathrm{CFU} \mathrm{g}{ }^{-1}$ ) of splenic tissue (M.W.R. unpubl. data). Lesions in fish from which $M$. shottsii has been cultured, however, have varied widely in severity, and clinical signs of disease have not always been present. This has also been true of fish that cultured positive for $M$. marinum and other mycobacteria. Further, co-infections of 2 or more mycobacterial species frequently occurred. Therefore, controlled experimental infections of striped bass were performed to elucidate the role of selected individual Mycobacterium spp. in production of disease.

The temporal progression of experimentally induced mycobacterial disease has been examined in a number of fish species, including plaice Pleuronectes platessa, seabass Dicentrarchus labrax, Atlantic salmon Salmo salar, and goldfish Carassius auratus (Timur et al. 1977, Bruno et al. 1998, Colorni et al. 1998, Talaat et al. 1998). Acute mycobacteriosis with rapid mortality $(\leq 8 \mathrm{~d})$ has been produced in striped bass via intramuscular injection of relatively high doses of Mycobacterium marinum (Wolf \& Smith 1999). As mycobacteriosis is generally considered to be a chronic disease of fish, pathology produced over long time periods by sublethal doses is relevant to understanding the disease process. To our knowledge, no studies have yet addressed the long-term pathogenesis of mycobacteria in striped bass.

In this study, we experimentally produced chronic infections in striped bass with the mycobacterial species Mycobacterium shottsii, M. marinum, and M. gordonae. M. gordonae, a common environmental isolate, is generally considered to be a non-pathogenic saprophyte, although cases of infection in humans have been reported (McIntyre et al. 1987, Lessnau et al. 1993). The lesions produced by the 3 mycobacterial species, as well as splenic bacterial density, were examined and compared at regular intervals over a 45 wk time period.

\section{MATERIALS AND METHODS}

Fish maintenance. Striped bass used in these experiments were obtained as fry from Harrison Lake National Fish Hatchery (Charles City, Virginia). Fish were maintained within an isolation facility in $1000 \mathrm{l}$ circular tanks supplied with $91 \mathrm{~min}^{-1}$ (daily total volume replacements $=13$ ) of heated spring water that was degassed and oxygenated to saturation prior to use. Illumination of the tanks was provided by a combination of fluorescent and natural lighting with photoperiod of the fluorescent lighting adjusted to match local conditions. Fish were maintained on a dry pellet diet and were treated in-tank with $1 \%$ sodium chloride $(\mathrm{w} / \mathrm{v})$ to alleviate stress each time they were handled. Effluent from tanks containing fish injected with mycobacteria was passed through a 1400 l circular tank containing naïve fish in order to detect horizontal waterborne transmission of the bacteria. Prior to release from the facility, all tank effluents were treated for a minimum contact time of 20 min with hypochlorite maintained at a diluted final concentration of $100 \mathrm{mg} \mathrm{l}^{-1}$. Prior to use in the studies, striped bass were maintained under the conditions described above, except that the tanks were located separate from the isolation facility and were illuminated with fluorescent light only. Mean initial weights (g) of fish in long- and short-term portions of this study were (mean $\pm \mathrm{SE}$ ) $113.1 \pm 2.4(\mathrm{n}=360)$ and $126.8 \pm 3.4(\mathrm{n}=168)$, respectively.

Mycobacteria. Mycobacterium marinum and $M$. shottsii used in these studies were isolated from splenic tissue of Chesapeake Bay striped bass. $M$. gordonae was isolated from a skin lesion of a Chesapeake Bay striped bass. Isolates were identified using traditional growth and biochemical tests (Kent \& Kubica 1985, Lévy-Frébault \& Portaels 1992). In addition, M. shottsii was characterized by antimicrobial sensitivity testing, HPLC mycolic acid analysis and 16S rRNA gene sequencing (Rhodes et al. 2001, 2003). M. marinum and M. shottsii were passed once intraperitoneally in striped bass and recovered from spleen homogenates by plating on Middlebrook 7H10 agar with OADC enrichment and 0.5\% glycerol (MDA). The inoculum of $M$. gordonae was obtained from an archived isolate maintained on MDA. Colonies from 
the primary isolation plates ( $M$. marinum, $M$. shottsii) or archived culture ( $M$. gordonae) were inoculated into Middlebrook 7H9 medium with OADC enrichment and $0.05 \%$ polyoxyethylenesorbitan monooleate (Tween 80) (MDB) and incubated at $23^{\circ} \mathrm{C}$ (M. shottsii) or $30^{\circ} \mathrm{C}$ (M. gordonae, M. marinum). M. gordonae and M. marinum prefer the higher growth temperature of $30^{\circ} \mathrm{C}$, whereas $M$. shottsii exhibits optimal growth at the lower temperature (Rhodes et. al. 2001). Suspensions of actively growing cultures, as determined turbidimetrically, were pelleted by centrifugation at $12000 \times g$ for 20 min and washed once in Butterfield's phosphate buffer (Anonymous 1995) with $0.05 \%$ Tween 80 (hereafter referred to as PB). Washed cultures were resuspended in buffer, vortexed vigorously with glass beads ( $\sim 50 \mu \mathrm{m}$ diameter) for $2 \mathrm{~min}$ and filtered through Whatman No. 1 paper to reduce clumping and obtain a homogeneous suspension. Absorbance at $590 \mathrm{~nm}$ was adjusted with PB to 0.05 , or approximately $10^{7} \mathrm{CFU} \mathrm{ml} l^{-1}$, and diluted tenfold in $\mathrm{PB}$ prior to injection.

Infection. At study initiation, striped bass were anaesthetised using $100 \mathrm{mg} \mathrm{l}^{-1}$ Finquel (MS-222, Argent Chemical), weighed, and injected intraperitoneally with $100 \mu \mathrm{l}$ of diluted mycobacterial suspension. In the long-term study, the dose $\left(\mathrm{CFU} \mathrm{g}{ }^{-1}\right.$ total body weight) of Mycobacterium marinum, M. gordonae, and $M$. shottsii delivered was (mean $\pm \mathrm{SE}, \mathrm{n}=$ 89 fish for each treatment) $2300 \pm 100,1400 \pm 70$, and $1500 \pm 90$, respectively. The dose of $M$. marinum ( $\mathrm{n}=$ $40 \mathrm{fish}), M$. gordonae ( $=40$ fish), and $M$. shottsii ( $\mathrm{n}=10$ fish) delivered in the short-term study was $($ mean \pm SE) $8700 \pm 200,3100 \pm 80$, and $17000 \pm 400$, respectively. The number of sham- (PB)-injected fish in the long- and short-term experiments was 89 and 40 , respectively.

Sampling interval. Fish used for the short-term (Group 1) and long-term (Group 2) portions of the study were maintained in separate tanks. The longterm experiment was initiated $10 \mathrm{wk}$ prior to the shortterm experiment. At each sampling, bass were sacrificed using a lethal dose of Finquel and weighed. Group 2 striped bass were sampled ( $\mathrm{n}=10$ unless otherwise noted) 8, 17, 26, 36 (Mycobacterium gordonae $\mathrm{n}=3$ ), and 45 wk p.i. ( $M$. gordonae $\mathrm{n}=0, M$. marinum $\mathrm{n}=7$ ). Group 1 samples ( $M$. marinum and $M$. gordonae $\mathrm{n}=5, M$. shottsii $\mathrm{n}=3$ ) were obtained biweekly beginning at Week 2 ( $M$. marinum and $M$. gordonae) or 4 ( $M$. shottsii) and ending at Week 8 p.i. For the first $26 \mathrm{wk}$ of the long-term experiment and the entire short-term experiment, water temperature was maintained at $18^{\circ} \mathrm{C}$. Water temperature increased to $21^{\circ} \mathrm{C} 4 \mathrm{~d}$ after the Week 26 sampling of Group 2 and was maintained at this level for the remainder of the study. The change in temperature was not planned and resulted from a switch to back-up heating following the failure of the primary system.

Bacteriology. Fish sacrificed at selected exposure intervals were aseptically necropsied. A portion of splenic tissue weighing 0.01 to $0.5 \mathrm{~g}$ was removed, weighed and transferred to a sterile Ten Broeck tissue grinder. Tissue was homogenized in $1.5 \mathrm{ml} \mathrm{PB}$ and tenfold serially diluted. Duplicate MDA plates were spread-plated with $0.2 \mathrm{ml}$ homogenate or dilutions thereof. Brain-heart infusion agar plates were inoculated with homogenate and monitored for non-acidfast bacterial contamination. Plates were incubated and examined at 6 to $8 \mathrm{wk}$ with final observations made at 3 mo. Representative colonies from each sample were acid-fast stained using the Ziehl-Neelsen method. Isolates from more than $1 / 2$ of samples positive for acid-fast colonies were biochemically characterized to confirm the identity of the isolate. Tests for phenotypic verification included pigmentation, Tween 80 hydrolysis, and production of arylsulfatase, nitrate reductase, niacin, pyrazinamidase, and urease (Kent \& Kubica 1985, Lévy-Frébault \& Portaels 1992).

Data analysis. Splenic mycobacterial densities are expressed as CFU g ${ }^{-1}$, and means are calculated from log-transformed data. Values preceded by ' $<$ ' indicate that at least 1 of the replicate samples was below the detection limit, and values preceded by ' $>$ ' indicate that colonies at the highest dilution plated were too numerous to count. Values below or above the detection level were entered as absolute values based on the lowest level of sensitivity or the highest dilution plated. All statistical analyses were performed with Statview (SAS Institute). Regression analysis of mycobacterial densities and time was performed using simple linear regression and the regression ANOVA table. Differences between infected groups were evaluated using the Friedman nonparametric '2-way ANOVA by ranks test' and the Mann-Whitney U-test. The Kendall rank correlation test was used to determine whether mycobacterial densities correlated with maturation of host response.

Histology. Fish tissues were fixed in $10 \%$ phosphatebuffered formalin for at least $72 \mathrm{~h}$ prior to processing. Samples of anterior kidney, liver, spleen, mesenteries, hindgut, and, occasionally, body wall were processed routinely for paraffin histology (Prophet et al. 1994). Samples of body wall were decalcified prior to processing. Sections were cut at $5 \mu \mathrm{m}$ and stained with haematoxylin and eosin (H\&E). Selected slides were also stained with the Ziehl-Neelsen acid-fast stain or ZiehlNeelsen preceded by a $24 \mathrm{~h}$ incubation in $10 \%$ periodic acid $\left(\mathrm{HIO}_{4}\right)\left(\mathrm{Nyk}_{\mathrm{k}}\right.$ \& O'Neill 1970). Hereafter, the former technique will be abbreviated ' $\mathrm{ZN}$,' and the latter will be abbreviated 'P-ZN.' All slides were examined on an Olympus AX-70 light microscope. 
Table 1. Morone saxatilis. Major histological features of lesion stages. Acid-fast staining described is unmodified Ziehl-Neelsen

\begin{tabular}{|cl|}
\hline $\begin{array}{c}\text { Lesion stage } \\
\text { Inflammatory focus/none } \\
(-)\end{array}$ & $\begin{array}{l}\text { Either no lesions, or lesions composed of loosely organized inflammatory cells. Few to no acid-fast } \\
\text { bacilli are observed within inflammatory foci }\end{array}$ \\
$\begin{array}{c}\text { Epithelioid granuloma } \\
\text { (I) }\end{array}$ & $\begin{array}{l}\text { Lesion is composed of centralized epithelioid cells surrounded by inflammatory cells. Eosino- } \\
\text { philic cellular debris may be present in lesion centre. Few to no acid-fast bacilli are present }\end{array}$ \\
$\begin{array}{c}\text { Spindle-cell granuloma } \\
\text { (II) }\end{array}$ & $\begin{array}{l}\text { Distinct necrotic core is separated from surrounding epithelioid cells by 1 or more layers of } \\
\text { flattened, highly eosinophilic spindle-shaped cells. Few to no acid fast bacilli are present }\end{array}$ \\
$\begin{array}{c}\text { Bacillary granuloma } \\
\text { (III) }\end{array}$ & $\begin{array}{l}\text { Numerous acid-fast bacilli are present in core and spindle cell layers. Spindle cell layers are } \\
\text { variable in thickness and may be incomplete }\end{array}$ \\
$\begin{array}{l}\text { Recrudescent lesion } \\
\text { (IV) }\end{array}$ & $\begin{array}{l}\text { Organization of granuloma is disrupted. Lesion cores are composed of intensely eosinophilic } \\
\text { and a wide margin of inflammatory cells may be present. Acid-fast bacilli are absent, sparsely } \\
\text { dispersed or present in clumps. Large lesions may replace majority of normal parenchyma in } \\
\text { affected organs }\end{array}$ \\
&
\end{tabular}

Lesion staging. H\&E-stained tissues were examined for the presence of granulomas, which were defined as lesions containing epithelioid cells. Fish not displaying lesions with epithelioid cells were classified as negative (-), although pre-granulomatous inflammatory foci may have been present. When granulomas were present, serial sections were stained with $\mathrm{ZN}$ or P-ZN to visualize acid-fast bacilli. A staging system was developed based on major morphologic characteristics of observed granulomas (Table 1). Fish displaying granulomas were assigned to 1 of 4 lesion stages, depending on the most advanced lesion present. Interpretation of the temporal progression of lesion development was based on the stages present relative to time elapsed post-infection (p.i.) (Table 2).

\section{RESULTS}

\section{Gross pathology}

External clinical signs observed in this study were nonspecific and could not be attributed to mycobacterial infection. Sampled fish in all groups, including sham-injected controls, were occasionally anorexic and/or dark in colour. Minor petechiae were observed on the venter of some infected fish, but grossly haemorrhagic skin ulcers similar to those seen on wild caught fish (Rhodes et al. 2001) were not present.

Nodular red foci were grossly visible in the mesenteries of both groups of Mycobacterium marinuminfected fish at all time points. These foci appeared to reach peak intensity at Weeks 8 (Group 1) and 17 (Group 2), at which point the entirety of the visceral fat was red, hardened, and fused into a solid mass. Numerous adhesions of this mass to the body wall were observed at these time points. Multiple red foci
Table 2. Morone saxatilis. Histological progression of granulomatous inflammation in mycobacteria-infected fish. Fish were assigned to a lesion stage category based on the most advanced lesion observed in sections. The number of fish having reached a particular lesion stage at each sampling point is presented. Stage descriptions are given in Table 1. Tissue types are abbreviated: anterior kidney $=\mathrm{AK}$, spleen $=$ SPL, mesentery = MES. Short- and long-term experiments are separated by the centre line. ns = not sampled

\begin{tabular}{|c|c|c|c|c|c|c|c|c|c|c|}
\hline \multirow[t]{2}{*}{ Tissue } & \multirow[t]{2}{*}{ Stage } & \multicolumn{9}{|c|}{-Weeks p.i. } \\
\hline & & 2 & 4 & 6 & 8 & 8 & 17 & 26 & 36 & 45 \\
\hline \multicolumn{11}{|c|}{ M. marinum } \\
\hline \multirow[t]{5}{*}{ SPL } & - & 5 & & & & & & & $1^{\mathrm{a}}$ & $1^{\mathrm{a}}$ \\
\hline & I & & 5 & 1 & & & & & & \\
\hline & II & & & 4 & 3 & 9 & 1 & 2 & & \\
\hline & III & & & & 2 & 1 & 9 & 7 & 7 & 4 \\
\hline & IV & & & & & & & 1 & 2 & 2 \\
\hline \multirow[t]{5}{*}{$\mathrm{AK}$} & - & 5 & & & & & & & & \\
\hline & I & & 4 & 3 & & & & & & \\
\hline & II & & 1 & 2 & 5 & 9 & 4 & 1 & & 1 \\
\hline & III & & & & & 1 & 6 & 8 & 5 & 2 \\
\hline & IV & & & & & & & 1 & 5 & 4 \\
\hline \multirow[t]{5}{*}{ MES } & - & 2 & & & & & & & & \\
\hline & I & 2 & & & & & & & & \\
\hline & II & 1 & 5 & 5 & 4 & 9 & 4 & 1 & & \\
\hline & III & & & & 1 & 1 & 6 & 8 & 6 & 4 \\
\hline & IV & & & & & & & 1 & 4 & 3 \\
\hline \multicolumn{11}{|c|}{ M. shottsii } \\
\hline \multirow[t]{5}{*}{ MES } & - & ns & 3 & 2 & & 8 & 8 & 10 & 7 & 9 \\
\hline & I & ns & & 1 & 1 & 1 & & & & \\
\hline & II & ns & & & 3 & 1 & 2 & & 2 & 1 \\
\hline & III & ns & & & & & & & 1 & \\
\hline & IV & ns & & & & & & & & \\
\hline \multicolumn{11}{|c|}{ M. gordonae } \\
\hline MES & - & 5 & 5 & 5 & 2 & 10 & 5 & 8 & & $\mathrm{~ns}$ \\
\hline & I & & & & 1 & & 1 & & & $\mathrm{~ns}$ \\
\hline & II & & & & 2 & & 4 & 2 & & $\mathrm{~ns}$ \\
\hline & III & & & & & & & & $2^{b}$ & $\mathrm{~ns}$ \\
\hline & IV & & & & & & & & & ns \\
\hline
\end{tabular}

${ }^{\text {a }}$ Spleens from these 2 fish were not available for histology ${ }^{\mathrm{b}}$ One sample was lost before histology could be performed 
were observed on the surface of the liver, and the spleen became progressively darkened and friable, with grey nodules. Buff-coloured or grey nodules were also present in the anterior kidney. Grossly visible inflammation of the viscera declined at 26 and $36 \mathrm{wk}$, whereas the visceral mass again appeared severely inflamed in fish sampled at $45 \mathrm{wk}$. Gross pathology in M. gordonae- and M. shottsii-infected fish was considerably less severe than that seen with $M$. marinum. Occasional red, nodular lesions were observed scattered among the visceral fat and mesenteries, but otherwise all internal organs appeared normal. Internal lesions were not seen in sham-injected fish.

\section{Histopathology}

Granulomatous lesions in fish infected with $\mathrm{Myco}$ bacterium marinum progressed through a series of morphologically distinct stages (Table 1). Lesion cell types and organization were histologically identical in spleen and anterior kidney, and differed in minor aspects from the mesenteries. Fish were assigned to a stage category based on the most advanced lesion observed; however, multiple granuloma stages were frequently present in individual fish.

\section{Inflammatory focus (-)}

Inflammatory foci in the mesenteries were readily distinguishable from normal parenchyma. Minor foci could be found in most fish examined, regardless of infection status. The structure of pre-granulomatous inflammatory foci, especially in Mycobacterium marinum-infected fish, however, differed from that of sham-injected fish. Small inflammatory foci, observed in both infected and, less frequently, in uninfected controls, were composed of loosely organized aggregations of macrophages, lymphocytes, and granulocytes. Macrophages and lymphocytes were rounded with basophilic cytoplasm and small, condensed nuclei. In fish injected with mycobacteria, inflammatory foci were greatly enlarged. A loose nodular organization was present in larger foci, and the interior of the lesion was composed of a branching network of basophilic cells (Fig. 1). Small, loosely organized basophilic cells were present around the periphery of this network, and eosinophilic granule cells (EGCs) were variably present. Acid-fast rods measuring approximately $4 \mu \mathrm{m}$ in length were observed in small numbers by P-ZN staining, but were rarely observed by ZN. Inflammatory foci in spleen and anterior kidney were not readily distinguishable from normal parenchyma.

\section{Epithelioid granuloma (Stage I)}

Epithelioid cells were tightly packed in the granuloma interior, contained homogeneous, slightly eosinophilic cytoplasm, and had enlarged nuclei with marginated heterochromatin. Vacuolization was occasionally observed. Larger epithelioid granulomas typically had a central region of intensely eosinophilic cellular debris containing pyknotic and karyorrhectic nuclei (Fig. 2a). Epithelioid granulomas in the spleen and anterior kidney were generally surrounded by a thin margin of basophilic cells, while a more extensive matrix of inflammatory cells surrounded mesenteric lesions. Acid-fast bacilli were rarely observed by ZN staining within epithelioid granulomas (Fig. 2b), although light, diffuse staining was occasionally present. P-ZN staining revealed varying numbers of bacilli, which were found in clumped aggregations within the necrotic core or singly in the surrounding epithelioid cells. These bacilli were polymorphic, ranging in length from $1 \mu \mathrm{m}$ to $4 \mu \mathrm{m}$, and beaded forms were present.

\section{Spindle cell granuloma (Stage II)}

Spindle cell granulomas were characterized by the presence of spindle-shaped cells with intensely eosinophilic cytoplasm and condensed nuclei. These cells formed a band that separated a distinct necrotic core from surrounding epithelioid layers (Fig. 2c), and appeared to be formed by flattening and elongation of the innermost layers of epithelioid cells. At later times

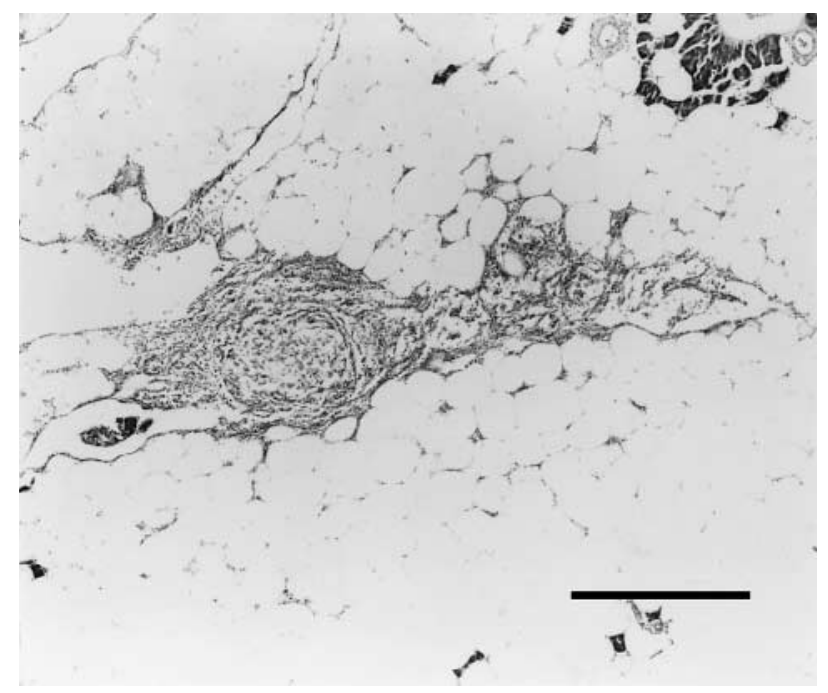

Fig. 1. Morone saxatilis. Pre-granulomatous inflammatory focus in mesentery of Mycobacterium marinum-infected striped bass. H\&E stain, scale bar $=100 \mu \mathrm{m}$ 


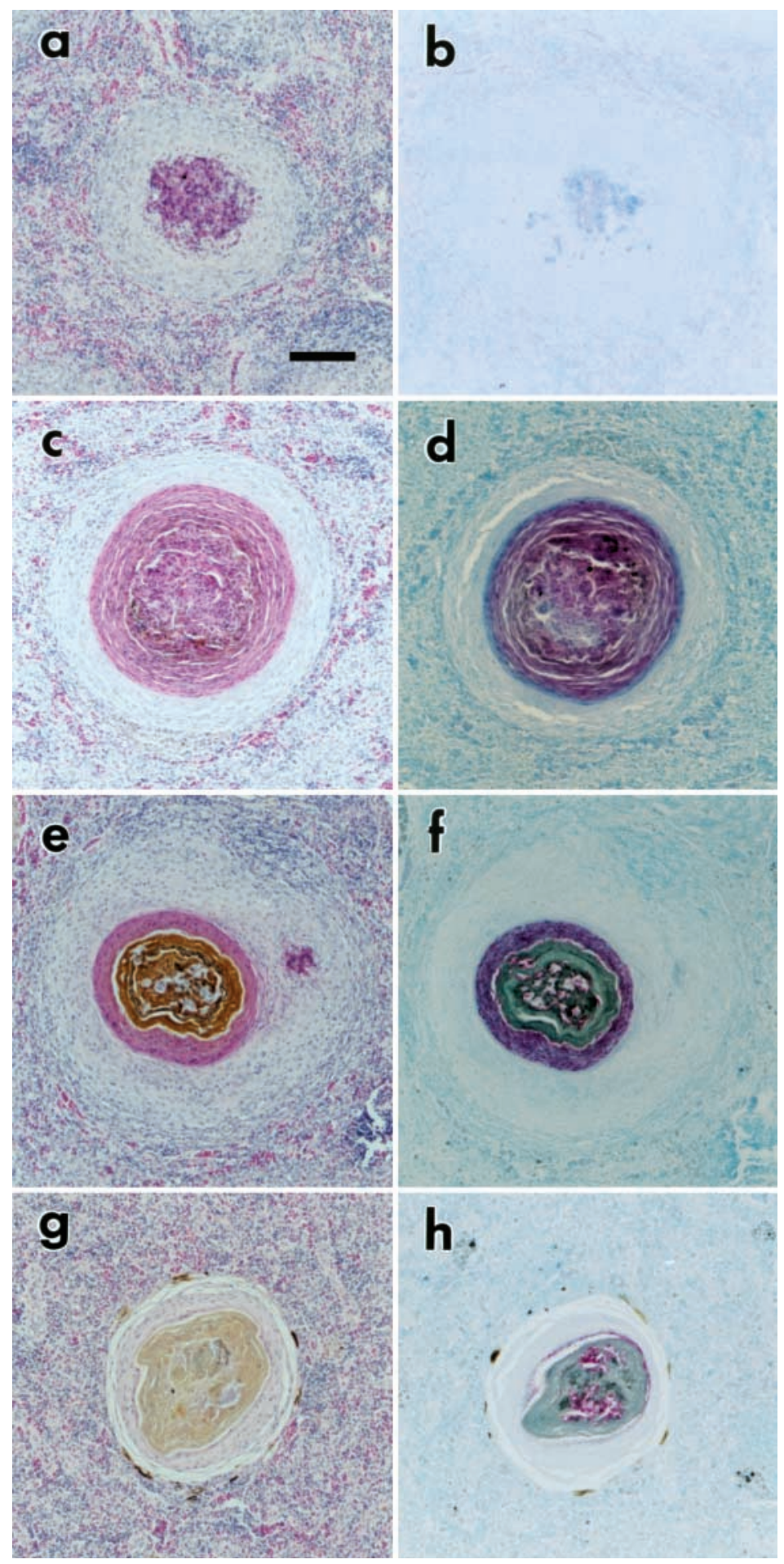

Fig. 2. Morone saxatilis. Progression of granuloma morphology in spleen of Mycobacterium marinum-infected striped bass. Left column is stained by H\&E, while right column is ZN stain of a close serial section. $(a, b)$ Epithelioid granuloma with centralized eosinophilic debris. (c,d) Spindle cell granuloma with well demarcated epithelioid and spindle-cell layers. $(\mathrm{e}, \mathrm{f})$ Bacillary granuloma with individual acid-fast bacilli in core and spindle-cell layers. $(g, h)$ Bacillary granuloma with attenuated spindle cell layers, lightly staining necrotic core, and acid-fast bacilli. Scale bar = $10 \mu \mathrm{m}$. All plates are at the same magnification p.i., Stage II granulomas typically had thick (>5 cells) spindle cell layers and enlarged necrotic cores with ceroid pigments. The presence and staining properties of acid-fast bacilli in spindle cell granulomas were similar to that of the epithelioid stage (Fig. 2d). In the anterior kidney and spleen, spindle cell granulomas were typically single, roughly spherical and circumscribed by a layer of flattened basophilic cells and/or connective tissue. Tissue parenchyma external to the granulomas appeared normal in organization and composition. In contrast, spindle cell granulomas in the mesenteries were surrounded by large margins of inflammatory cells and connective tissue. Frequently, adjacent granulomas appeared to fuse, creating large multinodular lesions surrounded by contiguous layers of spindle and epithelioid cells (Fig. 3a). Large numbers of EGCs were often present in the inflammatory tissue surrounding mesenteric spindle cell granulomas.

\section{Bacillary granuloma (Stage III)}

Bacillary granulomas were morphologically similar to spindle cell granulomas by H\&E staining, with the exceptions that epithelioid layers were somewhat reduced in thickness, and more ceroid pigment was present in the core (Fig. 2e). Granular basophilic material was also occasionally visible in the core debris. Both ZN and P-ZN techniques stained large numbers of individual, $4 \mu \mathrm{m}$ acid-fast bacilli. Bacilli were found in the core as well as intracellularly in the spindle cell layers (Fig. 2f). The diffuse acidfast staining previously observed by ZN was absent. Bacillary granulomas in all tissues were typically well demarcated by connective tissue capsules. In contrast to the extensive inflammatory tissue present around spindle cell granulomas in the mesenteries, the tissue surrounding bacillary granulomas showed evidence of healing and regeneration (Fig. 3b). Localized areas of inflammation were still present, and typically contained high numbers of EGCs. At later times p.i., bacillary granulomas with attenuated spindle cell layers and lightly staining cores were commonly observed (Fig. $2 g$ ). In these lesions, the spindle cell layers were reduced to 1 or 2 cell thicknesses or were absent, with 


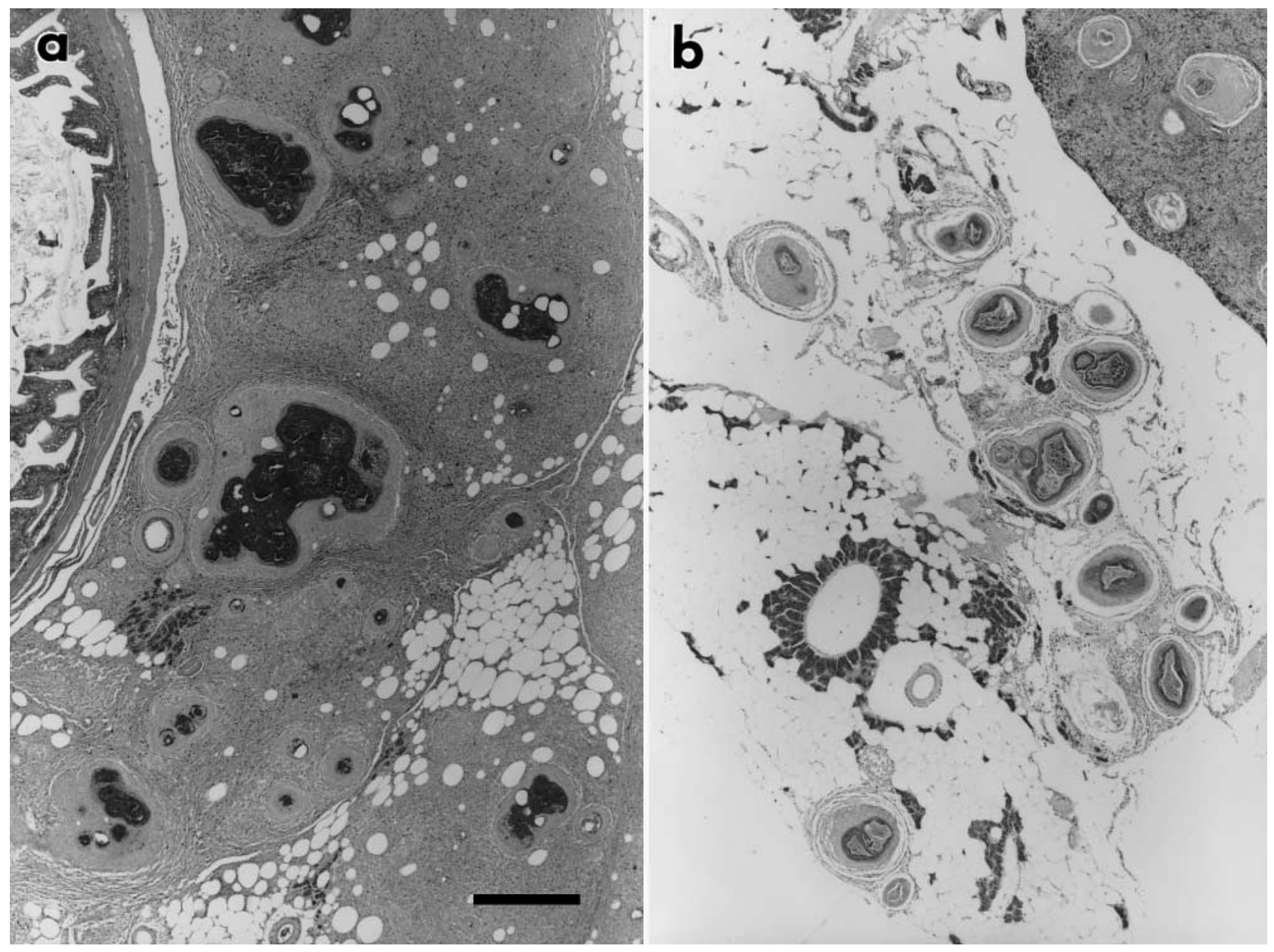

Fig. 3. Morone saxatilis. Mycobacterium marinum granulomas in mesenteries of striped bass. (a) Large, coalescing spindle-cell granulomas, with widespread inflammation and fibrosis in surrounding tissue (8 wk). (b) Bacillary granulomas surrounded by largely normal mesenteric tissue (26 wk). H\&E stain, scale bar $=100 \mu \mathrm{m}$

the core abutting directly on epithelioid cells. Acid-fast bacilli were demonstrable by ZN and P-ZN in the lesion core, as well as in areas where identifiable spindle cells remained (Fig. 2h). Acid-fast bacilli were rarely observed in surrounding epithelioid or normal tissue. The integrity of the epithelioid layers and surrounding connective tissue appeared to be maintained in all bacillary granulomas, but lesions with attenuated spindle cell layers were generally more polymorphic than earlier lesions.

\section{Recrudescent lesion (Stage IV)}

Disintegration of bacillary granulomas and widespread reappearance of inflammation in Mycobacterium marinum-infected fish was observed beginning at 26 wk p.i. Bacillary lesions of all forms, including those with thick spindle cell layers, were observed in the process of disintegration. In smaller recrudescent lesions, spindle cells layers were absent or disrupted, and the necrotic material of the core was replaced with amorphous, intensely eosinophilic cells containing condensed nuclei, similar to those seen in epithelioid granulomas (Fig. 4a). A wide, amorphous border of epithelioid and inflammatory cells surrounded the lesions. Larger recrudescent lesions often displaced considerable areas of the parenchyma in affected tissues (Fig. 4b). The core of these lesions was highly expanded and typically composed of foamy, eosinophilic debris, although a cellular core with pyknotic and karyorrhectic nuclei was occasionally present. Fluid-filled, cystic lesions were also observed. In some cases, the disorganized remnant of a bacillary granuloma containing many acid-fast bacilli was observed within recrudescent lesions. Both ZN and P-ZN techniques stained acid-fast bacteria in recrudescent lesions, although the latter typically revealed larger 


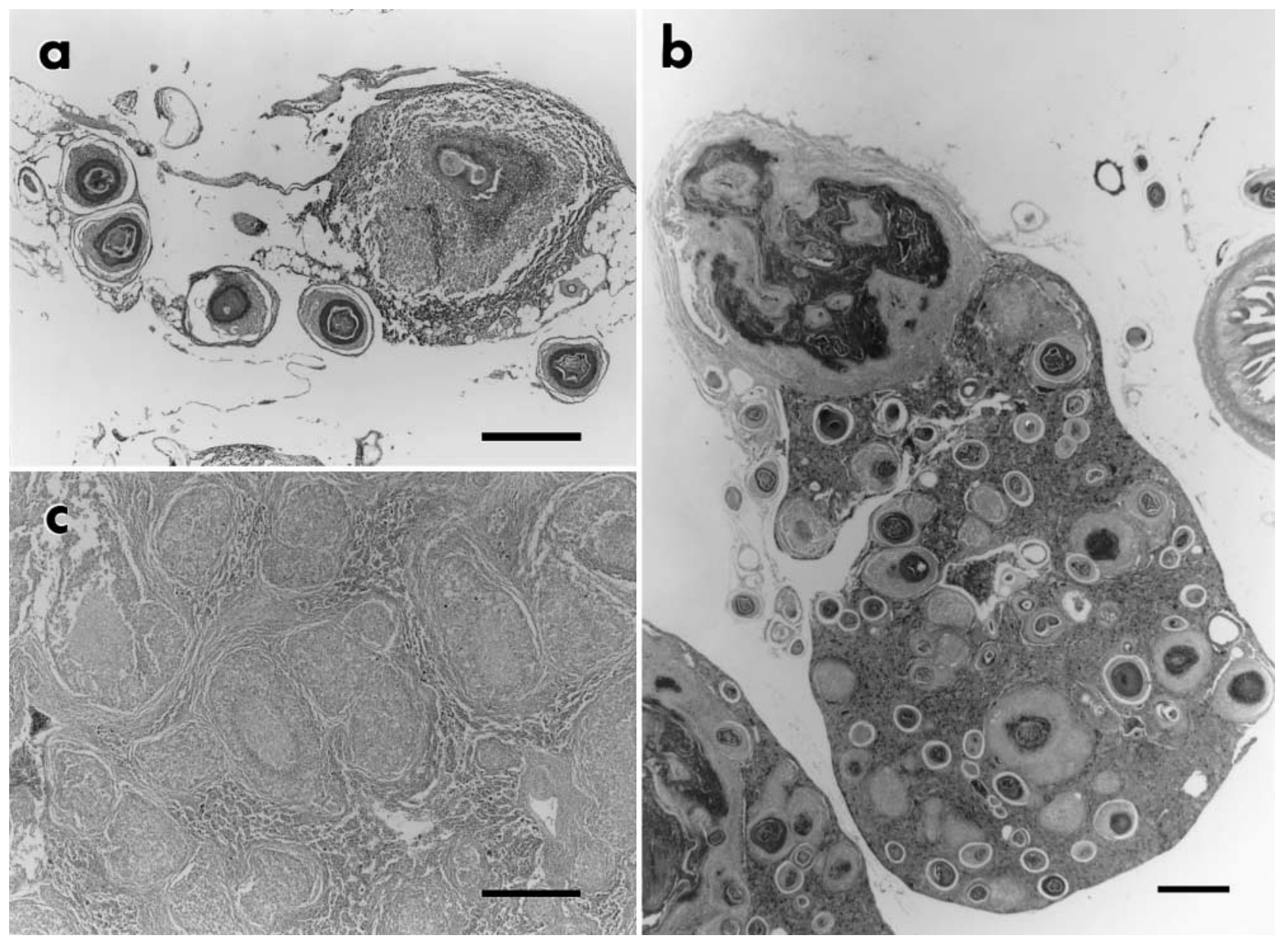

Fig. 4. Morone saxatilis. Progression of recrudescent lesions in Mycobacterium marinum-infected fish. (a) Bacillary granulomas and small recrudescent lesion (mesentery, $26 \mathrm{wk}$ ). Integrity of spindle cell and epithelioid layers is compromised, necrotic core material is replaced with eosinophilic cell debris, and inflammation is renewed around the lesion. (b) Advanced recrudescent lesion (spleen, $36 \mathrm{wk}$ ). Lesion containing core of foamy eosinophilic material occupies a large portion of the organ. (c) Advanced recrudescent lesion (anterior kidney, $45 \mathrm{wk}$ ). Entire parenchyma of pronephros is replaced with nodular organizations of inflammatory tissue and fibrosis. H\&E stain, scale bars $=100 \mu \mathrm{m}$

numbers of bacteria. In some cases, large areas of recrudescent lesions were acid-fast-negative.

In 1 of 7 Mycobacterium marinum-infected fish at 45 wk p.i., the entirety of the anterior kidney and the majority of the spleen were replaced by nodular organizations of loosely packed inflammatory cells and extensive fibrosis (Fig. 4c). Both ZN and P-ZN stains revealed large numbers of acid-fast bacilli within the nodules and in the surrounding connective tissue. Grossly, the anterior kidney was enlarged and composed entirely of buff-coloured nodules, and the posterior kidney had completely degenerated. The spleen was largely composed of grey nodules and was friable. Similar lesions were observed in a second M. marinum-infected fish at $45 \mathrm{wk}$, but lesions did not occupy as much of the affected organs.
Granulomas in fish infected with either Mycobacterium shottsii or $M$. gordonae were similar in morphology and progression to those of $M$. marinuminfected fish. These lesions, however, were smaller and greatly reduced in number. With the exception of 1 spindle cell granuloma in the anterior kidney of a single $M$. shottsii-infected fish, granulomas were restricted to the mesenteries. Also, the degree of inflammation observed in the mesenteries of $M$. shottsii- or M. gordonae-infected fish did not approach that seen with $M$. marinum. Bacillary granulomas were observed in only $1 M$. shottsii- and $2 M$. gordonae- infected fish throughout the course of the study, and recrudescent lesions did not occur.

Granulomas were observed in 1 sham-injected fish in both Groups 1 and 2 at the 8 wk sample and from 1 
sham-injected fish obtained from Group 2 at Week 17. The single granuloma in the Group 1 fish was acidfast-negative and resembled parasitic granulomas observed in wild-caught striped bass. Well-developed spindle cell granulomas were present in the liver of the Group 2 fish at Week 8. These granulomas had acid-fast interiors, although bacilli were not visible. No mycobacteria were isolated from the spleen of this fish. One small, ZN-negative, poorly organized granuloma was observed in the anterior kidney of the $17 \mathrm{wk}$ fish, and no mycobacteria were recovered from the spleen.

Granulomatous inflammation due to Mycobacterium marinum progressed in a similar manner in all affected organs (Table 2). Epithelioid and spindle cell granulomas were present in the mesenteries of infected fish at the first sampling (2 wk). In both spleen and anterior kidney, epithelioid granulomas were present at $4 \mathrm{wk}$, and spindle cell granulomas at $6 \mathrm{wk}$. At 8 wk, bacillary granulomas were present in mesenteries of 1 fish from both experimental groups, in the spleen of 2 fish from Group 1 and 1 fish from Group 2, and in the anterior kidney of 1 fish from Group 2. From 17 wk onward, the majority of fish had bacillary granulomas in all 3 tissues. Recrudescent lesions were observed in anterior kidney, spleen, and mesenteries of a single fish at $26 \mathrm{wk}$, and in all organs of at least 2 sampled fish thereafter.

In Mycobacterium shottsii-infected fish, mesenteric spindle cell granulomas were not observed until $8 \mathrm{wk}$, and bacillary granulomas were present in 1 fish at $36 \mathrm{wk}$ p.i. With the exception of Group 1 fish at $8 \mathrm{wk}$, granulomas were present in a minority of fish sampled (Table 2).

Granuloma progression in Mycobacterium gordonaeinfected fish was similar to that seen with $M$. shottsii. Spindle cell granulomas were observed at $8 \mathrm{wk}$ in Group 1, and at 17 wk in Group 2 fish. Interestingly, small bacillary granulomas were present in both of the $M$. gordonae-infected fish examined histologically at Week 36.

In general, the morphology and progression of granulomas associated with the liver was similar to that seen in other organs. The majority of these granulomas were located in the mesenteries surrounding the liver, among exocrine pancreatic cells, or surrounding blood vessels passing through the organ. Most granulomas directly involving the parenchyma appeared to have originated peripherally and eventually incorporated liver tissue. Therefore, it was difficult to ascertain which, if any, granulomas had arisen entirely within the liver parenchyma. Bacillary granulomas and recrudescent lesions did significantly impact liver tissue at later times p.i. with $M$. marinum.

\section{Bacteriology}

Acid-fast colonies were selected from 101 of 175 culture-positive fish, isolated, and examined phenotypically. All isolates recovered were confirmed to be mycobacterial species injected at the beginning of the study, with 1 exception. In this instance, co-infection with a second mycobacterium was detected with $\mathrm{CFU} \mathrm{g}{ }^{-1} 1$ order of magnitude lower that the injected isolate, Mycobacterium shottsii. Acid-fast colonies from sham samples ( $\mathrm{n}=42$ fish) were observed on 6 occasions but were phenotypically different from the 3 injected isolates. No granulomas were observed in the tissues of these fish. One of 7 uninjected fish in the tank exposed to effluent from other holding tanks was positive for $M$. marinum, containing $3.7 \times 10^{5} \mathrm{CFU} \mathrm{g}^{-1}$ splenic tissue. Epithelioid granulomas were observed in the anterior kidney and liver, but not the spleen or mesenteries, of this fish.

Splenic densities of the 3 mycobacterial species in infected fish over the course of this study are shown in Figs. 5 (short-term experiment) \& 6 (long-term experi-
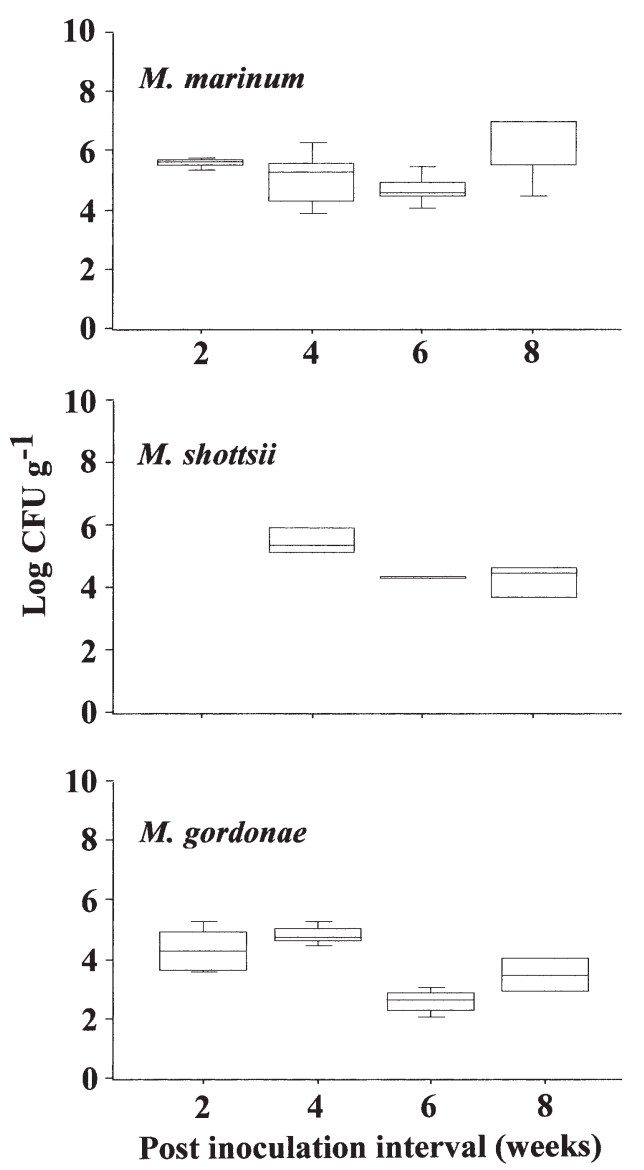

Fig. 5. Morone saxatilis. Box plots of splenic mycobacterial density (colony forming units, $\mathrm{CFU}, \mathrm{g}^{-1}$ ) vs time post-inoculation in the short-term experiment. Horizontal lines, from top to bottom, represent 10th, 25th, 50th (median), 75th, and 90th percentiles 

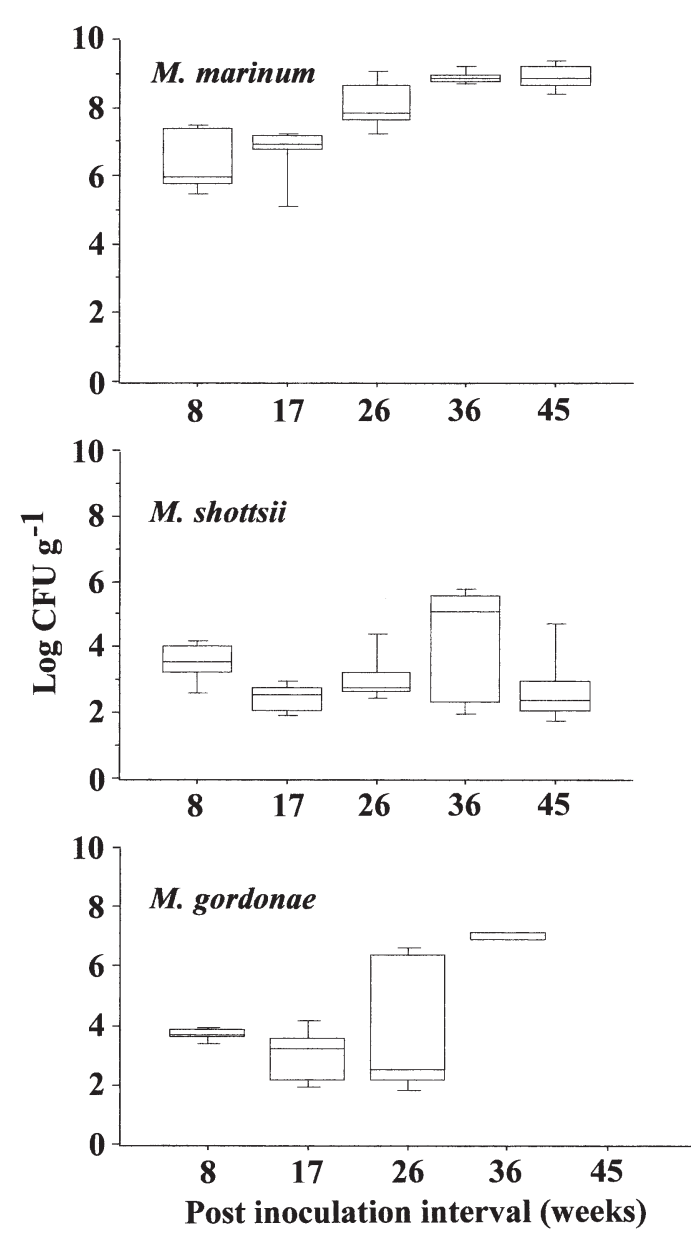

Fig. 6. Morone saxatilis. Box plots of splenic mycobacterial density $\left(\mathrm{CFU} \mathrm{g}{ }^{-1}\right)$ vs time post-inoculation in the long-term experiment. Horizontal lines, from top to bottom, represent 10th, 25th, 50th (median), 75th, and 90th percentiles

ment). Mean Mycobacterium marinum concentrations increased approximately 1 order of magnitude between 4 and 8 wk in Group 1, whereas mean $M$. shottsii and $M$. gordonae densities decreased by greater than 1 order of magnitude. In Group 2, mean densities of $M$. marinum reached $\sim 10^{9} \mathrm{CFU} \mathrm{g}^{-1}$ at 36 and $45 \mathrm{wk}$. Regression analysis revealed a significant relationship ( $\mathrm{p}<0.0001$ ) between $M$. marinum cell densities and time. Mean densities of $M$. shottsii ranged from $<3.2 \times 10^{2} \mathrm{CFU} \mathrm{g}^{-1}$ to $<1.6 \times 10^{4} \mathrm{CFU} \mathrm{g}^{-1}$, and mean densities of $M$. gordonae ranged from $<1.3 \times$ $10^{3} \mathrm{CFU} \mathrm{g}^{-1}$ to $>1.3 \times 10^{7} \mathrm{CFU} \mathrm{g}^{-1}$ over the course of the long-term experiment. The high upper figure for the latter is derived from the $3 \mathrm{M}$. gordonae-infected fish remaining at Week 36. From wk 8 to 26, mean $M$. gordonae densities peaked at $>7.9 \times 10^{3} \mathrm{CFU} \mathrm{g}^{-1}$. Between 8 and $36 \mathrm{wk}$ in the long-term experiment, splenic mycobacterial densities of inoculated fish differed significantly $(p<0.05)$ depending on species. Hetero- geneity in mycobacterial loads between fish was characteristic of all groups but was particularly pronounced for $M$. gordonae- and M. shottsii-injected fish. Mean densities of $M$. gordonae and $M$. shottsii remained significantly lower than $M$. marinum ( $\mathrm{p} \leq$ 0.006) throughout the long-term experiment, with maximum concentrations of approximately $10^{7}$ and $10^{6} \mathrm{CFU} \mathrm{g}^{-1}$, respectively, occurring in individual fish.

There was no correlation of mycobacterial concentration and lesion stage for any mycobacterial species in the short-term experiment. However, a highly significant correlation ( $\mathrm{p} \leq 0.0002)$ was found in the long-term experiment between splenic Mycobacterium marinum densities and lesion progression (i.e. Stages -, I, II, III, IV) in the spleen and mesentery. $M$. gordonae-injected fish exhibited a significant $(\mathrm{p}=$ 0.031) correlation between splenic mycobacterial burden and maturation of mesenteric granulomas. No such correlation was found in M. shottsii-infected fish.

\section{DISCUSSION}

Experimentally induced piscine mycobacteriosis typically involves an initial acute inflammatory response to injected mycobacteria, followed by the development of a chronic granulomatous disease state with low associated mortality (Bruno et al. 1998, Colorni et al. 1998). Using goldfish as an experimental model, Talaat et al. (1998) demonstrated that mean survival time and transition to the chronic granulomatous state was dependent on the initial dose of Mycobacterium marinum. Acute peritonitis, reduced granuloma formation, and high mortality were observed in fish receiving $10^{8}$ to $10^{9}$ bacteria, whereas fish receiving $10^{7}$ bacteria survived to the end of the study and exhibited welldeveloped granulomas. Acute mycobacteriosis with high mortality has also been produced in striped bass by high-dose intramuscular $M$. marinum exposure (Wolf \& Smith 1999). In the present study, injection of M. marinum produced acute inflammation in the peritoneal cavity, which abated concomitantly with the development of mature granulomas in all organs. Splenic bacterial load remained roughly constant during the development of mature granulomas between 8 and 17 wk p.i. After 17 wk, however, considerable bacterial replication occurred within granulomas, as reflected by both splenic counts and the histological appearance of acid-fast rods. This replication preceded a phase of granuloma disintegration and reappearance of acute, fulminant disease. These results indicate piscine mycobacteriosis may transition between phases of chronic granuloma formation and acute disseminative disease, in a manner similar to mammalian mycobacterioses such as tuberculosis (Cotran et al. 
1999). The cues for this transition in mammals remain poorly understood, but immune suppression of the host is generally recognized as a factor in reactivation disease (Parrish et al. 1998). Whether the recrudescence of mycobacterial disease observed in this study was precipitated directly by the mycobacteria or by an exogenous, immunomodulatory factor is unknown at this time.

The closely related species Mycobacterium marinum and $M$. shottsii (Rhodes et al. 2001, 2003) produced very different pathology in the striped bass of this study. Both mycobacteria established persistent infections in the spleen, but granulomatous inflammation in spleen and anterior kidney was observed, with 1 exception, only in $M$. marinum-infected fish. Whereas M. marinum produced severe pathology and a secondary phase of reactivation disease, mesenteric inflammation due to $M$. shottsii was considerably less severe, and mesenteric granulomas very rarely contained large numbers of ZN-detectable bacteria. In addition, mean densities of $M$. marinum in the spleen exceeded those of $M$. shottsii by approximately 3 orders of magnitude at the later time points of the study. Unlike the M. shottsii-infected fish in this study, wild-caught fish from which M. shottsii is the sole isolate often display severe granulomatous disease (M.W.R. unpubl. data). These findings strongly suggest that in the wild, $M$. shottsii can cause disease similar to that produced by M. marinum in this study. Under the experimental conditions of this study, $M$. shottsii was able to establish a persistent, latent infection state. Several factors, such as temperature, salinity, or fish stress may be involved in the activation of these infections in wild fish. These factors may also be involved in the production of skin lesions in wildcaught fish (Vogelbein et al. 1999, Rhodes et al. 2001), which were not observed after injection with any mycobacterial species in this study.

In Mycobacterium marinum-infected fish, the transition from spindle cell granulomas to bacillary granulomas and, in 1 fish, recrudescent lesions had already begun in all organs before the water temperature shift from 18 to $21^{\circ} \mathrm{C}$ occurred. Therefore, it is unlikely that elevated temperature was solely responsible for the observed progression of disease. It is possible, however, that the elevated temperature accelerated the growth of $M$. marinum and exacerbated the pathology seen at 36 and 45 wk. M. gordonae- and M. shottsiiinfected fish did not exhibit bacillary granulomas until $36 \mathrm{wk}$, after the temperature shift. Only $1 \mathrm{M}$. shottsii fish developed these lesions, and only $2 \mathrm{M}$. gordonaeinfected fish were sampled histologically after $26 \mathrm{wk}$, however, so no substantive evidence was found that the temperature shift was responsible for disease progression.
The putatively non-pathogenic Mycobacterium gordonae was persistent in the spleens of striped bass throughout the course of the study and produced mesenteric granulomas identical in form to those produced by $M$. shottsii. Bacillary granulomas in $M$. gordonae-infected fish at 36 wk suggest that this mycobacterium is capable of survival for long periods of time in the striped bass host. Another presumably non-pathogenic mycobacterium, M. smegmatis, has also been shown to be pathogenic in fish (Talaat et al. 1999). These results indicate that so-called 'environmental isolates' such as $M$. gordonae may play a role in mycobacterial disease of wild or aquacultured fish stocks.

During development of granulomas to the spindle cell stage, acid-fast bacilli were rarely demonstrated by the commonly used Ziehl-Neelsen technique. Truant's fluorescent acid-fast stain and Taylor's gram stain were also applied in an attempt to demonstrate cryptic mycobacteria, without improvement over ZN. Pretreatment with periodic acid, however, revealed mycobacteria in serial sections that were negative by ZN. This technique has been shown to increase staining of chromophobic forms of Mycobacterium tuberculosis and $M$. leprae in tissue sections and smears (Nyka \& O'Neill 1970, Harada 1977), as well as M. marinum in broth culture (Dhople 1985). Although the existence of acid-fast and non-acid-fast mycobacteria has long been recognized, the chemical basis for this variation remains unknown, and the clinical significance of chromophobic forms is still debated. Several researchers have suggested the acid-fastness of mycobacteria may be dependent on their replicative or physiologic state, with bacteria in log phase being more chromophobic than those in stationary phase (Reich 1971, Dhople 1985). In this study, however, the presence of bacillary granulomas correlated with a nearly 80-fold increase in mean splenic CFU g ${ }^{-1}$, suggesting actively replicating $M$. marinum were not chromophobic. In fish that had not yet developed bacillary granulomas, nearly all bacilli present within lesions appeared to be chromophobic, but large numbers of mycobacteria were cultured. These observations indicate that viable chromophobic forms of $M$. marinum were present within granulomas of infected striped bass. It is possible that these forms represent a resting state, and are capable of reversion to their original acid-fast form given appropriate conditions or stimuli.

Demonstration of acid-fast, unbranched rods in tissue sections or smears is considered diagnostic for Mycobacterium spp. in fish (van Duijn 1981). As demonstrated here, however, mycobacteria present in early granulomas may not stain by unmodified ZN. Mycobacterial lesions with few or no acid-fast bacilli have also been described at early time points in exper- 
imentally infected seabass (Colorni et al. 1998) and in wild yellow perch Perca flavescens (Daoust et al. 1989). In the latter study, the use of Fite's acid-fast stain improved detection of acid-fast bacilli. Therefore, the type of stain used, as well as the stage of mycobacterial infection, may strongly influence the detection of acidfast bacilli. This indicates that caution should be used in the interpretation of acid-fast-stained tissues from fish, and that mycobacterial infection should not be ruled out on the basis of a negative $\mathrm{ZN}$ stain in fish displaying granulomas.

Detection of mycobacteria by culturing can also be problematic. Recovery of mycobacteria from granulomatous lesions can be hindered by the use of harsh disinfectants, inappropriate culture conditions (e.g. media, temperature, duration of incubation) and the fastidiousness of the causative agent (Shotts \& Teska 1989, Rhodes et al. 2003). Generally, no attempt is made to perform quantitative analyses of the mycobacterial burden in infected tissues. In the present study, the need to reduce contaminating bacteria with chemical agents was avoided with careful aseptic necropsy. Cultural conditions were also maximized to enhance recovery by using a mildly selective medium (MDA) and incubating at an environmentally relevant temperature for an extended time period. Combining these cultural methods with a quantitative assay enabled assessments of mycobacterial densities during disease progression.

Spindle cell and bacillary granulomas observed in this study were similar to those described in wild and aquacultured striped bass (Sakanari et al. 1983, Hedrick et al. 1987), as well as wild Chesapeake Bay fish (W.K.V. unpubl. data). Large numbers of acid-fast bacilli were demonstrated by unmodified $\mathrm{ZN}$ in mycobacterial granulomas by Hedrick et al. (1987) and Sakanari et al. (1983), suggesting these fish may have been in a similar state of disease as fish with bacillary granulomas in this study. It is not known, however, how long bacillary granulomas remain intact within striped bass, or if the presence of bacillary granulomas necessarily leads to recrudescent disease. The progression of disease in experimentally infected striped bass may eventually be used to interpret histological findings in wild fish, but the influence of several environmental factors on this progression must first be examined before such parallels can be drawn.

In order to assess the potential for horizontal waterborne transmission of mycobacteria, uninjected striped bass were maintained in a tank receiving effluent water from all other tanks containing infected fish. One of 7 fish sampled from this tank at Week 45 had epithelioid granulomas in the anterior kidney and liver, while the spleen and mesentery were free of inflammation. Mycobacterium marinum was isolated from the spleen of this fish at a density of $3.7 \times 10^{5} \mathrm{CFU}$ $\mathrm{g}^{-1}$. This indicates $M$. marinum is shed by infected fish, and that fish may obtain infections from the water. Further studies will be necessary to confirm this finding.

Acknowledgements. The authors thank P. Blake, D. Booth, L. Iwanowicz, and D. Zwerner for technical assistance, as well as Drs. V. Blazer, C. Densmore, and S. Kaattari for critical review. This work was supported by US Geological Survey Cooperative Research Agreement \#01ERAG0015.

\section{LITERATURE CITED}

Anonymous (1995) Bacteriological analytical manual. US Food and Drug Administration, AOAC International, Gaithersburg, MD

Backman S, Ferguson HW, Prescott JF, Wilcock BP (1990) Progressive panophthalmitis in chinook salmon, Oncorhynchus tshawytscha (Walbaum): a case report. J Fish Dis 13:345-353

Bruno DW, Griffiths J, Mitchell CG, Wood BP, Fletcher ZJ, Drobniewski FA, Hastings TS (1998) Pathology attributed to Mycobacterium chelonae infection among farmed and laboratory-infected Atlantic salmon (Salmo salar). Dis Aquat Org 33:101-109

Cardinal JL (2001) Mycobacteriosis in striped bass, Morone saxatilis, from Virginia waters of Chesapeake Bay. MSc thesis, Virginia Institute of Marine Science

Colorni A (1992) A systemic mycobacteriosis in the European sea bass Dicentrarchus labrax cultured in Eilat (Red Sea). Isr J Aquacult Bamidgeh 44:75-81

Colorni A, Avtalion R, Knibb W, Berger E, Colorni B, Timan B (1998) Histopathology of sea bass (Dicentrarchus labrax) experimentally infected with Mycobacterium marinum and treated with streptomycin and garlic (Allium sativum) extract. Aquaculture 160:1-17

Cotran RS, Kumar V, Collins T (1999) Pathologic basis of disease. WB Saunders, Philadelphia

Daoust PY, Larson BE, Johnson GR (1989) Mycobacteriosis in yellow perch (Perca flavescens) from two lakes in Alberta. J Wildl Dis 25:31-37

Dhople AM (1985) Influence of prior periodic acid oxidation on the acid-fastness of Mycobacterium leprae. IRCS (Int Res Commun Syst ) Biomed Technol 13:1259-1260

Gómez S, Bernabé A, Gómez MA, Navarro JA, Sánchez J (1993) Fish mycobacteriosis: morphopathological and immunocytochemical aspects. J Fish Dis 16:137-141

Harada K (1977) Staining mycobacteria with periodic acidcarbol-pararosanilin: principle and practice of the method. Microscopica Acta 79:224-236

Heckert RA, Elankumaran S, Milani A, Baya A (2001) Detection of a new Mycobacterium species in wild striped bass in the Chesapeake Bay. J Clin Microbiol 39:710-715

Hedrick RP, McDowell T, Groff J (1987) Mycobacteriosis in cultured striped bass from California. J Wildl Dis 23: 391-395

Kent PT, Kubica GP (1985) Public health mycobacteriology: a guide for the level III laboratory. US Department of Health and Human Services, Publication no. (CDC) 86-8230. Centers for Disease Control, Atlanta

Landsell W, Dixon B, Smith N, Benjamin L (1993) Isolation of several Mycobacterium species from fish. J Aquat Anim Health 5:73-76

Lessnau KD, Milanese S, Talavera W (1993) Mycobacterium 
gordonae: a treatable disease in HIV-positive patients. Chest 104:1779-1785

Lévy-Frébault VV, Portaels F (1992) Proposed minimal standards for the genus Mycobacterium and for description of new slowly growing Mycobacterium species. Int J Syst Bacteriol 42:315-323

McIntyre P, Blacklock Z, McCormack JG (1987) Cutaneous infection with Mycobacterium gordonae. J Infect Dis 14: $71-78$

Nigrelli RF, Vogel H (1963) Spontaneous tuberculosis in fish and other coldblooded vertebrates with special reference to Mycobacterium fortuitum from fish and human lesions. Zoologica 48:131-144

Nyka W, O'Neill EF (1970) A new approach to the study of nonacid-fast mycobacteria. Ann NY Acad Sci 174:862-871

Parrish NM, Dick JD, Bishai WR (1998) Mechanisms of latency in Mycobacterium tuberculosis. Trends Microbiol 6:107-112

Prophet EB, Mills B, Arrington JB, Sobin LH (1994) Laboratory methods in histotechnology. Armed Forces Institute of Pathology, American Registry of Pathology, Washington, DC

Reich CV (1971) A comparison of the growth curves of the NQ bacillus (Mycobacterium sp.) derived by photometric turbidity, microscopic counting, and viability in a tubedilution-series. Int J Lepr Other Mycobact Dis 39:25-33

Rhodes MW, Kator H, Kotob S, van Berkum P and 7 others (2001) A unique Mycobacterium species isolated from an epizootic of striped bass (Morone saxatilis). Emerg Infect Dis $7: 1-3$

Rhodes MW, Kator H, Kotob S, van Berkum P and 6 others (2003) Mycobacterium shottsii sp. nov., a slowly growing species isolated from Chesapeake Bay striped bass (Morone saxatilis). Int J Syst Evol Micro 53:421-424

Editorial responsibility: David Bruno,

Aberdeen, Scotland, UK
Sakanari JA, Reilly CA, Moser M (1983) Tubercular lesions in Pacific Coast populations of striped bass. Trans Am Fish Soc 112:565-566

Shotts EB, Teska JD (1989) Bacterial pathogens of aquatic vertebrates. In: Austin B, Austin DA (eds) Methods for the microbiological examination of fish and shellfish. Ellis Horwood, John Wiley \& Sons, New York, p 164-186

Talaat AM, Reimschuessel R, Wasserman SS, Trucksis M (1998) Goldfish, Carassius auratus, a novel animal model for the study of Mycobacterium marinum pathogenesis. Infect Immun 66:2938-2942

Talaat AM, Trucksis M, Kane AS, Reimschuessel R (1999) Pathogenicity of Mycobacterium fortuitum and $\mathrm{Myco}$ bacterium smegmatis to goldfish, Carassius auratus. Vet Microbiol 66:151-164

Timur G, Roberts RJ, McQueen A (1977) The experimental pathogenesis of focal tuberculosis in the plaice (Pleuronectes platessa L.). J Comp Path 87:83-87

Tortoli E, Bartoloni A, Bozzetta E, Burrini C and 5 others (1996) Identification of the newly described Mycobacterium poriferae from tuberculous lesions of snakehead fish (Channa striatus). Comp Immun Microbiol Infect Dis 19:25-29

van Duijn C (1981) Tuberculosis in fishes. J Small Anim Pract 22:391-411

Vogelbein WK, Zwerner DE, Kator H, Rhodes M, Cardinal J (1999) Epizootic mycobacteriosis in Chesapeake Bay striped bass. In: Cipriano RC (ed) 24th Annual Eastern Fish Health Workshop, Atlantic Beach, NC. National Fish Health Research Laboratory, Kearneysville, WV

Wolf JC, Smith SA (1999) Comparative severity of experimentally induced mycobacteriosis in striped bass Morone saxatilis and hybrid tilapia Oreochromis spp. Dis Aquat Org 38:191-200

Submitted: October 3, 2002; Accepted: December 23, 2002 Proofs received from author(s): March 20, 2003 